\title{
Comparison of growth inhibition and immunofluorescence tests in serotyping clinical isolates of Ureaplasma urealyticum
}

\author{
PETER PIOT \\ From the Laboratory of Bacteriology, Instituut voor Tropische Geneeskunde, Antwerp, Belgium
}

SUMMARY Typestrains of the eight serotypes of Ureaplasma urealyticum and 39 genital isolates were typed by the growth inhibition (GI) and indirect immunofluorescence (IF) tests. The GI test proved to be very specific and simple, demanding large volumes of serum. It was less sensitive than the IF test, which produced more cross-reactions, was economical in serum, and able to detect mixed infections. Of the 39 isolates, 27 were serotyped by GI and 34 by IF. Mixed cultures occurred in as many as $36 \%$ of the isolates.

\section{Introduction}

Many well conducted studies have not proved an aetiological role for Ureaplasma urealyticum in non-gonococcal urethritis (NGU). Freundt (1973), Morton (1975), and Dunlop (1975) have reviewed studies on this subject.

A quantitative approach to the problem, as advocated by Shepard (1974), especially in cases of Chlamydia-negative NGU could support a pathogenic role for $U$. urealyticum in the aetiology of NGU and deserves further investigation.

Another approach is the analysis of the different serotypes of the $U$. urealyticum strains recovered. At present at least eight serotypes have been described (Shepard et al., 1974).

In a previous study from this laboratory (Piot, 1976) the growth inhibition (GI) test was used to type 46 clinical isolates of $U$. urealyticum. Among the different techniques proposed, the indirect immunofluorescence (IF) test eventually combined with the GI test has been recommended as the test of choice for serotyping mycoplasmas (Freundt, 1974).

The purpose of this study was to compare the sensitivity and specificity of the IF test with the GI test and to determine the suitability of these tests for the routine serotyping of clinical isolates of $U$. urealyticum.

\footnotetext{
Address for reprints: Dr Peter Piot, Laboratory of Bacteriology, Instituut voor Tropische Geneeskunde, Nationalestraat 155, B-2000 Antwerp, Belgium

Received for publication 2 August 1976
}

\section{Materials and methods}

\section{STRAINS}

Thirty-nine $U$. urealyticum strains were isolated from urethral specimens taken from 10 male patients with gonorrhoea, 17 with NGU, and from 12 healthy men as described earlier (Piot, 1976). Clinical isolates were lyophilised without cloning. Reference strains of the eight serotypes of $U$. urealyticum were obtained from E. A. Freundt, FAO/WHO International Centre for Animal Mycoplasmas, Aarhus, Denmark.

\section{MEDIA}

The ureaplasma strains were propagated on L-medium consisting of proteose peptone no. 3 (Difco) $1.5 \%, \mathrm{NaCl} 0.5 \%$, fresh yeast extract (baker's yeast) $2.5 \%$, fresh horse plasma $12 \%$, ion agar no. 2 (Oxoid) $1.1 \%$, phosphate buffer $\left(\mathrm{KH}_{2} \mathrm{PO}_{4}-\mathrm{Na}_{2} \mathrm{HPO}_{4}\right) 20 \%, \mathrm{pH} \mathrm{6.2,} \mathrm{distilled} \mathrm{water}$ $62 \cdot 3 \%$.

\section{SEROLOGICAL TESTS}

The GI test was performed according to a modification of Black's technique as described previously (Piot, 1976). The L-medium was preheated at $37^{\circ} \mathrm{C}$ for 60 minutes and one drop $(0.01 \mathrm{ml})$ of an overnight Ureaplasma culture $\left(10^{4}-10^{5}\right.$ colony forming units $/ \mathrm{ml}$ ) was distributed on the agar plate by the running drop technique; $0.025 \mathrm{ml}$ of antiserum was applied in a $4 \mathrm{~mm}$ well and the plates were incubated at $32^{\circ} \mathrm{C}$ in air with $10 \% \mathrm{CO}_{2}$ for 48 hours. The plates were examined under a stereomicroscope after 
application of a mixture of $1 \%$ urea and $0.8 \%$ manganous sulphate (Shepard, 1973). Zones of growth inhibition were measured from the edge of the wells to the edge of colony development. Only zones of $0.5 \mathrm{~mm}$ or greater were regarded as significant.

The IF test of Rosendal and Black (1972) using unfixed colonies on agar was used under slightly modified conditions: agar blocks, approximately $0.5 \times 0.5 \mathrm{~cm}$ in size, supporting between two and five colonies, were placed on slides and incubated with one drop of diluted typing antiserum for 30 minutes at room temperature in a moist chamber. The blocks were rinsed twice in phosphate buffered saline (PBS) $(\mathrm{pH} \mathrm{7.2)}$ for 10 minutes and incubated for 30 minutes at room temperature with one drop of conjugated sheep antirabbit globulin (Institut Pasteur, Paris) diluted at 1:50, followed by two rinses in PBS (pH 7.2) for 10 minutes. The labelled blocks were then kept in PBS (pH 7.2) at $4^{\circ} \mathrm{C}$ in a moist chamber for 24 hours, the PBS being changed twice.

They were examined under a Leitz fluorescence microscope with incident illumination. Titres are given as the reciprocal of the highest dilutions of antisera causing strong fluorescence.

Antisera were provided by M. C. Shepard and were incubated at room temperature with an equal volume of medium for one hour before use.

\section{Results}

\section{GROWTH INHIBITION}

When the method outlined was followed, the GI test was easy to read and provided zones of inhibition from 1 to $5 \mathrm{~mm}$. Standardisation of the inoculum was found to be critical, a large inoculum $\left(>10^{5}\right.$ colony forming units $/ \mathrm{ml}$ ) resulting in significantly smaller zones of inhibition, or no inhibition at all. As stated by Black (1973) larger zones of inhibition were obtained by lowering the incubation temperature to $27^{\circ} \mathrm{C}$ but below $30^{\circ} \mathrm{C}$ some strains became inconsistent and scanty, even with prolonged incubation.

The test proved to be very specific when performed with the eight reference strains against their homologous antisera; only one cross-reaction occurred: between antiserum type II and Ureaplasma serotype $\mathrm{V}$, as already mentioned by Black (1970).

Of the 39 clinical isolates 26 were readily serotyped, while 12 isolates were not inhibited by any of the sera used. One isolate showed large inhibition zones ( 3 and $4 \mathrm{~mm}$ respectively) with antisera types II and VI and diminished growth inside each zone, uggesting a mixed culture.
IMMUNOFLUORESCENCE

Non-specific background fluorescence made the interpretation of the IF test doubtful and nonreproducible until the final 24-hour rinse in PBS was introduced. This did not decrease the intensity of specific fluorescence and had no effect on the attachment of the colonies to the medium.

All IF reactions were read without knowledge of the results of the GI test, and with coded antisera. The titres of the antisera against the eight type strains examined in reciprocal cross-immunofluorescence tests are given in Table 1. With the exception of antisera against serotypes IV and VII, all homologous titres were higher than $1 / 80$, and antiserum to serotype I even reached $1 / 1280$. One way cross-reactions were observed with three antisera: antiserum II with serotypes I and V, antiserum IV with serotype II, and antiserum VIII with serotypes IV and VII. These cross-reactions reached values identical with the homologous reactions or were one-half to one-quarter of these.

Serotyping of clinical isolates was done with the sera diluted to the titres as indicated in Table 1 so that cross-reactions owing to lack of specificity of the typing sera may be expected to occur for types VIII, VII and IV, II and V, and IV and II.

Clear results were obtained in 19 cases $(50 \%)$; the colonies of four strains did not fluoresce, and 15 gave strong fluorescence with only one of the antisera (four with type II, one with type IV, one with type VI, four with type VII, and five with type VIII).

Results were more difficult to interpret in 20 cases $(50 \%)$ : one isolate gave a weak reaction with four antisera and should probably be interpreted as negative. Nineteen isolates fluoresced strongly with more than one of the antisera. Mixed cultures, consisting of serotypes presenting no cross-reactions (Table 1), were clearly observed in 11 cases: some colonies fluoresced with one particular antiserum on part of the block, while on other blocks some colonies fluoresced with a different antiserum. The remaining eight isolates fluoresced strongly with two different sera which showed cross-reactions in the reciprocal cross-immunofluorescence tests with the eight typestrains. Of these, five strains fluoresced with antisera II and IV, and three strains with sera IV and VIII. When tested by GI, five of these isolates (three reacting with II and IV, and two with IV and VIII) presented a clear zone of inhibition with only one antiserum (three types II, two types IV). They were considered as single serotypes. The remaining three cultures (two types II and IV and one types IV and VIII) gave no inhibition at all in the GI test, which may be caused by the presence 
Table 1 Relationship between eight ureaplasma strains measured by indirect immunofluorescence

\begin{tabular}{|c|c|c|c|c|c|c|c|c|}
\hline \multirow[b]{2}{*}{ U. urealyticum serotypes } & \multicolumn{8}{|c|}{ Antiserum against serotypes } \\
\hline & $\boldsymbol{I}$ & $\boldsymbol{I I}$ & III & $I V$ & $\boldsymbol{V}$ & $V I$ & $V I I$ & VIII \\
\hline I & 1280 & 40 & $<10$ & $<10$ & $<10$ & $<10$ & $<10$ & $<10$ \\
\hline II & $<10$ & 160 & $<10$ & 20 & $<10$ & $<10$ & $<10$ & $<10$ \\
\hline III & $<10$ & $<10$ & 640 & $<10$ & $<10$ & $<10$ & $<10$ & $<10$ \\
\hline IV & $<10$ & $<10$ & $<10$ & 40 & $<10$ & $<10$ & $<10$ & 160 \\
\hline V & $<10$ & 160 & $<10$ & $<10$ & 320 & $<10$ & $<10$ & $<10$ \\
\hline VI & $<10$ & $<10$ & $<10$ & $<10$ & $<10$ & 160 & $<10$ & $<10$ \\
\hline VII & $<10$ & $<10$ & $<10$ & $<10$ & $<10$ & $<10$ & 80 & 320 \\
\hline VIII & $<10$ & $<10$ & $<10$ & $<10$ & $<10$ & $<10$ & $<10$ & 320 \\
\hline
\end{tabular}

of more than one serotype. Although there is not the same evidence of their being mixtures as in the previous cases, they are considered as such in the discussion of the results. In all, therefore, it seemed that 14 of the isolates consisted of more than one serotype occurring in the following combinations in the populations studied: I and II (two), I and III, I and IV, I and VI, I and VIII, II and IV (two), II and VI, II and VII, II and VIII (three), IV and VIII.

\section{COMPARISON OF GI AND IF}

Table 2 presents the results of the serotyping of 39 clinical isolates by both methods. Three strains typed by GI were identified differently by IF: one (GI) serotyped $\mathrm{V}$ gave strong fluorescence with antiserum VII only, while two (GI) serotypes VII could not be typed by IF. The mixed culture detected by GI was confirmed by IF.

Immunofluorescence revealed an additional serotype in six isolates typed by GI and it was able to identify nine of 12 which gave no growth inhibition. Two of these isolates belonged to only one serotype (VII and VIII) the remaining cultures containing two serotypes of $U$. urealyticum.

\section{Discussion}

In the current study neither the IF nor the GI test alone was entirely satisfactory for serotyping clinical isolates of $U$. urealyticum. The GI test is specific and relatively easy to perform. However it has several disadvantages. Relatively large volumes of typing sera are needed, since these have to be used undiluted. It is relatively insensitive: of the 39 isolates, $27(69 \%)$ were serotypes by GI test as compared with $34(87 \%)$ by IF (Table 2$)$. Furthermore the GI method is much less able to detect mixed cultures than the IF test. Previous cloning is no solution to this problem since it could precisely mask the occurrence of such mixtures.

The high titres obtained in the IF test makes it economical in the volumes of sera to be used. We
Table 2 Results of serotyping 39 isolates of $\mathrm{U}$. urealyticum by the growth inhibition and the immunofluorescence tests

\begin{tabular}{lllcc}
\hline Test & $\begin{array}{l}\text { Tested } \\
\text { strains }\end{array}$ & $\begin{array}{l}\text { One } \\
\text { serotype }\end{array}$ & $\begin{array}{l}\text { Mixed } \\
\text { culture }\end{array}$ & $\begin{array}{l}\text { Strains } \\
\text { not typed }\end{array}$ \\
\hline Growth inhibition & 39 & 26 & 1 & 12 \\
Immunofluorescenco & 39 & 20 & 14 & 5 \\
\hline
\end{tabular}

observed more cross-reactions than those reported by Black and Krogsgaard-Jensen (1974) who mentioned only one strong cross-reaction between antiserum II with serotype V. The cross-reactions we observed were reproducible.

Other advantages over the GI test are the possibility of identifying non-viable colonies (up to two months old, if stored at $4^{\circ} \mathrm{C}$ in a moist chamber) and the production of results in 24 hours.

The classification of $U$. urealyticum in eight serotypes is suitable for epidemiological studies, since only three isolates out of $39(8 \%)$ could not be typed with these eight antisera using the GI and IF tests.

The high incidence $(36 \%)$ of mixed cultures in this study is noteworthy and confirms the observation of Lin and Kass (1973) on 10 strains which were typed by a complement-dependent mycoplasmacidal test. This figure may be lower than the real incidence as only subcultures were examined and not the primary isolation plates, and as only a small number of colonies were tested.

The occurrence of a mixture of serotypes is not surprising since a close correlation has been found between sexual activity and colonisation with genital mycoplasmas (McCormack et al., 1972).

It can be concluded that clinical isolates of $U$. urealyticum should be screened with the IF test and that all isolates presenting strong cross-reactions or doubtful results be examined with the GI test.

I thank Professor E. A. Freundt, FAO/WHO International Reference Center for Animal Mycoplasmas, Aarhus, for providing reference strains of 
$U$. urealyticum and antisera against $M$. hominis and $M$. fermentans, Dr M. C. Shepard, Naval Medical Field Research Laboratory, Camp Lejeune, for generously supplying the antisera against the serotypes of $U$. urealyticum.

\section{References}

Black, F. T. (1970). Serological methods for classification of human T-mycoplasmas. Proceedings of 5 th International Congress for Infectious Diseases, Vienna, Vol. I, pp. 407-411. Edited by K. K. Spitzy and H. Radl. Wiener Medizinischen Akademie: Vienna.

Black, F. T. (1973). Modification of the growth inhibition test and its application to human T-mycoplasmas. Applied Microbiology, 25, 528-533.

Black, F. T., and Krogsgaard-Jensen, A. (1974). Application of indirect immunofluorescence, indirect haemagglutination and polyacrylamide-gel electrophoresis to human T-mycoplasmas. Acta pathologica et microbiologica Scandinavica, Section B, 82, 345-353.

Dunlop, E. M. C. (1975). Non-specific genital infection. Laboratory aspects. In Recent Advances in Sexually Transmitted Diseases, pp. 267-295. Edited by R. S. Morton and J. R. W. Harris. Churchill Livingstone: London.

Freundt, E. A. (1973). Present status of the medical importance of mycoplasmas. Pathologia et microbiologia, 40, 155-187.

Freundt, E. A. (1974). Practical aspects of serological identification. In Les mycoplasmes de l'homme, des animaux, des végétaux et des insectes, pp. 161-168. J. M. Bové and J. F. Duplan. INSERM: Paris.
Lin, J.-S., and Kass, E. H. (1973). Serotypic heterogenicity in isolates of human genital T-mycoplasmas. Infection and Immunity, 7 , 499-500.

McCormack, W. M., Almeida, P. C., Bailey, P. E., Gardy, E. M., and Lee, Y.-H. (1972). Sexual activity and vaginal colonization with genital mycoplasmas. Journal of the American Medical Association, 221, $1375-1377$.

Morton, R. S. (1975). Non-specific genital infection. Clinical aspects. In Recent Advances in Sexually Transmitted Diseases, pp. 257-266. Edited by R. S. Morton and J. R. W. Harris. Churchill Livingstone: London.

Piot, P. (1976). Distribution of eight serotypes of Ureaplasma urealyticum in cases of non-gonococcal urethritis and of gonorrhoea, and in healthy persons. British Journal of Venereal Diseases, 52, 266-268.

Rosendal, S., and Black, F. T. (1972). Direct and indirect immunofluorescence of unfixed and fixed mycoplasma colonies. Acta pathologica et microbiologica Scandinavica, Section B, 82, 345-353. Shepard, M. C. (1973). Differential methods for identification of T-mycoplasmas based on demonstration of urease. Journal of Infectious Diseases, 127, S22-S25.

Shepard, M. C. (1974). Quantitative relationship of Ureaplasma urealyticum to the clinical course of non-gonococcal urethritis in the human male. In Les mycoplasmes de l'homme, des animaux, des végétaux et des insectes, pp. 375-379. J. M. Bové and J. F. Duplan. INSERM: Paris.

Shepard, M. C., Lunceford, C. D., Ford, D. K., Purcell, R. H., Taylor-Robinson, D.,Razin, S., and Black, F. T. (1974). Ureaplasma urealyticum gen.nov., sp.nov.: Proposed nomenclature for the human T (T-strain) mycoplasmas. International Journal of Systematic Bacteriology, 24, 160-171. 